\title{
Consumo, Digestibilidade Total e Desempenho de Novilhos Nelore Recebendo Dietas Contendo Diferentes Proporções de Silagens de Brachiaria brizantha cv. Marandu e de Sorgo ${ }^{1}$
}

\author{
Fernanda Helena Martins Chizzotti ${ }^{2}$, Odilon Gomes Pereira ${ }^{3,5}$, Sebastião de Campos Valadares \\ Filho $^{3,5}$, Rasmo Garcia ${ }^{3,5}$, Mario Luiz Chizzotti ${ }^{4}$, Maria Ignêz Leão ${ }^{3}$, Dalton Henrique Pereira ${ }^{4}$
}

\begin{abstract}
RESUMO - Avaliaram-se o consumo e a digestibilidade total dos nutrientes e o desempenho de novilhos Nelore recebendo dietas contendo silagens de capim-braquiarão e de sorgo como fonte de volumoso nas proporções de 100:0, 67:33, 33:67 e 0:100, com base na matéria seca. Foram utilizados 24 novilhos Nelore, castrados, com peso médio inicial de $380 \mathrm{~kg}$, distribuídos em um delineamento em blocos casualizados, com seis repetições, recebendo $60 \%$ de volumoso e $40 \%$ de concentrado, com base na matéria seca. O ensaio teve duração de 78 dias - 15 dias de adaptação seguidos de três períodos de 21 dias. Os consumos médios de matéria seca (MS), matéria orgânica (MO), proteína bruta (PB), extrato etéreo (EE), carboidratos não-fibrosos (CNF) e nutrientes digestíveis totais (NDT), assim como a taxa de passagem, aumentaram linearmente com o incremento da silagem de sorgo nas dietas. Tendência semelhante foi observada para o ganho de peso médio diário, estimando-se acréscimos de $0,00313 \mathrm{~kg} /$ unidade de silagem de sorgo adicionada. As digestibilidades totais de MS, MO, PB e fibra em detergente neutro (FDN) também apresentaram comportamento linear crescente com o incremento dos níveis de silagem de sorgo. Contudo, as digestibilidades aparentes do EE e dos CNF não foram influenciadas pelas dietas, registrando-se, respectivamente, valores médios de 80,1 e 89,5\%. A associação de 67\% de silagem de sorgo e 33\% de silagem de capim-braquiarão consistiu em como boa alternativa de volumoso para a alimentação de novilhos Nelore, uma vez que promoveu consumo e ganho de peso próximos aos observados para a dieta contendo apenas silagem de sorgo.
\end{abstract}

Palavras-chave: confinamento, fibra em detergente ácido indigestível, produção

\section{Intake, Apparent Total Tract Digestibility and Production of Nellore Steers Fed Diets Containing Different Proportions of Brachiaria brizantha cv. Marandu and Sorghum Silages}

\begin{abstract}
The objective of this trial was to study intake, apparent total tract digestibility, and production of Nellore steers fed diets containing the following ratios of Brachiaria brizantha and sorghum silages: 100:0, 67:33, 33:67, and 0:100 on dry matter (DM) basis. Twenty-four castrated steers averaging $380 \mathrm{~kg}$ at the beginning of the trial and receiving a forage:concentrate ratio of 60:40 (DM basis) were used in a randomized complete block design (six replicates per treatment). The experiment lasted 78 days with three 21 -days periods and 15 days for diet adaptation. The average intakes of DM, organic matter (OM), crude protein (CP), ether extract (EE), nonfiber carbohydrates (NFC), and total digestible nutrients (TDN) as well as passage rate all increased linearly with the increment of sorghum silage in the diet. Similarly, average body weight gain increased $0.00313 \mathrm{~kg}$ per unit of sorghum silage included in the diet. Apparent total tract digestibilities of DM, OM, CP, and neutral detergent fiber (NDF) also increased linearly when sorghum silage replaced Brachiaria brizantha silage in the diet whereas those of EE and NFC did not change significantly averaging 80.1 and $89.5 \%$, respectively. It can be concluded that a Brachiaria brizantha:sorghum silages ratio of 67:33 can be fed to Nellore steers because it resulted in similar intake and body weight gain compared to the diet containing only sorghum silage.
\end{abstract}

Key Words: indigestible acid detergent fiber, feedlot, production

\section{Introdução}

O uso de forrageiras conservadas na dieta de bovinos tem sido muito comum entre os pecuaristas, uma vez que a pastagem, durante a época seca do ano, é incapaz de fornecer os nutrientes em qualidade e quantidade suficientes. Essa prática, além de suprir a deficiência de forragem, também fornece alimentos de qualidade satisfatória para manter os índices produtivos e reprodutivos do rebanho durante o ano. Entretanto, é preciso programar a atividade de conservação considerando-se a forrageira a ser conservada e o processo mais adequado às necessidades do rebanho (Nussio, 2003).

Atualmente, em decorrência da competitividade na produção pecuária, da necessidade de redução dos custos e de aumento da produtividade, a silagem de

\footnotetext{
${ }^{1}$ Parte da tese de Mestrado do primeiro autor apresentada ao Programa de Pós-Graduação em Zootecnia/UFV.

2 Zootecnista, MS, Doutoranda, DZO-UFV, bolsista do CNPq. E.mail: fernandahm@bol.com.br

3 Professor do DZO - UFV. E.mail: odilon@ufv.br

${ }^{4}$ Estudante de doutorado do DZO-UFV.

${ }^{5}$ Bolsista do CNPq.
} 
capim tem conquistado a preferência dos produtores. $\mathrm{O}$ desenvolvimento de técnicas de emurchecimento, de inoculantes microbianos e de máquinas mais eficientes para colheita também foi de fundamental importância para o aumento da utilização da silagem de capim.

Entre as espécies forrageiras, as do gênero Brachiaria apresentam destacada participação no mercado brasileiro por se adaptarem às mais variadas condições climáticas e de solo. Estima-se que existam no Brasil aproximadamente 115 milhões de hectares de pastagens cultivadas e que $80 \%$ desta área seja ocupada pelas espécies do gênero Brachiaria (Anualpec, 2003). Assim, a realização de estudos envolvendo ensilagem de capins deste gênero justifica-se pelo fato de essas gramíneas ocuparem a maior área de pastagens cultivadas no país, principalmente no Brasil Central. Dessa forma, a ensilagem destes capins representa uma alternativa para os produtores, pois a forrageira já se encontra estabelecida em muitas propriedades, tornando seu custo menor, se comparado à elaboração de silagem de espécies convencionais, como milho e sorgo, ou de feno. Contudo, apesar do crescente espaço ocupado pelas silagens de capins, os estudos sobre ensilagem de capins do gênero Brachiaria na literatura ainda são muito escassos e, em sua maioria, são conduzidos em silos laboratoriais (Ribeiro et al., 2002; Mari, 2003). Portanto, é importante a avaliação dessas gramíneas em ensaio com animais, propiciando maior segurança aos produtores em decisões quanto à alimentação de seus rebanhos.

Outra opção largamente utilizada como fonte de volumoso é a silagem de sorgo. Consagrado na produção de silagem de boa qualidade, o sorgo tem se destacado como uma das principais alternativas para a alimentação de ruminantes, por sua rusticidade e resistência a deficiências hídricas ocasionais e pragas. O grande potencial do sorgo para ensilagem deve-se, principalmente, ao seu elevado teor de carboidratos solúveis, que garante adequada fermentação no interior do silo, sem a necessidade do uso de aditivos (Zago, 2002).

Muitas pesquisas têm sido conduzidas visando avaliar o efeito do processo de ensilagem de forrageiras sobre o consumo de nutrientes e o desempenho animal. Todavia, a maioria desses estudos tem avaliado diferentes proporções de concentrado na dieta, raramente envolvendo associação de volumosos. Segundo Allen (1996), o alimento volumoso como componente da dieta tem papel fundamental na manutenção das fun- ções ruminais, como fonte de energia e no desempenho dos rebanhos. O uso de combinações entre alimentos volumosos pode ser uma maneira viável de otimização do consumo, melhorando a ingestão de nutrientes e reduzindo o custo da dieta, visto que seriam necessárias quantidades menores de concentrado.

O valor nutritivo de um alimento é determinado pelo consumo e pela digestibilidade e eficiência com que os nutrientes são utilizados para mantença e produção (Raymond, 1969). O consumo de nutrientes é o principal fator associado ao desempenho animal, pois é determinante no atendimento às exigências de mantença e produção de ruminantes, podendo ser influenciado pelas características do animal, do alimento e das condições de alimentação. Segundo Mertens (1994), o consumo voluntário é responsável por 60 a $90 \%$ da variação no potencial de produção animal e apenas 40 a 10\% dessa produção pode ser atribuída à digestibilidade e à eficiência de utilização dos alimentos.

Além do consumo e da composição bromatológica dos alimentos, é importante o conhecimento da utilização dos nutrientes pelo animal, que é obtido a partir de estudos sobre a digestão. Muitos fatores influenciam a digestibilidade, incluindo a composição e o preparo dos alimentos e os fatores dependentes do animal e do nível nutricional (McDonald et al., 1995).

Este trabalho foi realizado objetivando-se avaliar o consumo e a digestibilidade total dos nutrientes e o desempenho de novilhos Nelore recebendo dietas contendo diferentes proporções de silagens de Brachiaria brizantha cv. Marandu e de sorgo.

\section{Material e Métodos}

O experimento foi realizado no período de julho a setembro de 2002 nas dependências da Central de Experimentação, Pesquisa e Extensão do Triângulo Mineiro (CEPET), pertencente à Universidade Federal de Viçosa. A CEPET localiza-se no município de Capinópolis, na região do Pontal do Triângulo Mineiro, à uma altitude média de 620,2 m, latitude Sul de 18,41o e longitude Oeste de 49,34 . O clima é do tipo Aw, segundo classificação de Köppen, quente e úmido, com temperatura do mês mais frio acima de $18^{\circ} \mathrm{C}$, estação chuvosa no verão e seca no inverno e precipitações médias anuais de 1.400 a $1.600 \mathrm{~mm}$. 
Em novembro de 2001, efetuou-se a semeadura do capim-braquiarão (Brachiaria brizantha cv. Marandu), em uma área de aproximadamente 5 ha, utilizando-se plantadeira SHM 1113, da Semeato. Nesta ocasião, foram aplicados $250 \mathrm{~kg} / \mathrm{ha}$ da mistura 8-28-16 e, 40 dias depois do plantio, efetuou-se adubação de cobertura, aplicando-se $180 \mathrm{~kg} / \mathrm{ha}$ da mistura 20-05-20. A colheita do capim foi realizada dos 101 aos 110 dias após o plantio, durante a fase de emborrachamento, com auxílio de uma máquina colhedora de forragem da Casale, modelo CFC 1800, efetuando-se à ensilagem, sem emurchecimento, em silos tipo superfície.

O plantio do sorgo forrageiro (Volumax) também foi efetuado em novembro de 2001 em área da CEPET destinada à produção de silagem. Foram aplicados 300 kg/ha de 8-28-16 como adubação de plantio, efetuando-se, ainda, duas adubações de cobertura aos 25 e 45 dias pós-semeadura, com 150 kg/ha da mistura 20-0-20 e 100 kg/ha de uréia, respectivamente. A colheita foi realizada quando os grãos atingiram o estádio farináceo-duro, aos 118 dias pós-semeadura, utilizando-se máquina colhedora de forragem JF, modelo JF90, procedendo-se à ensilagem em dois silos tipo superfície, com capacidade de, aproximadamente, 50 toneladas cada um.

Foram utilizados 24 novilhos Nelore, castrados, com peso médio inicial de $380 \mathrm{~kg}$, distribuídos em um delineamento em blocos casualizados, com quatro tratamentos e seis repetições, adotando-se o peso como critério para distribuição dos animais nos blocos. Inicialmente, os animais foram pesados, vermifugados e distribuídos por sorteio em baias individuais com área total de $10 \mathrm{~m}^{2}$, com cocho coberto e bebedouros cilíndricos de alvenaria.

Os tratamentos ( $\mathrm{T}$ ) consistiram de dietas isoprotéicas, balanceadas para conterem aproximadamente 12,5\% de proteína bruta, com relação volumoso:concentrado 60:40, com base na matéria seca, apresentando, respectivamente, as seguintes proporções de silagens de Brachiaria brizantha cv. Marandu e de sorgo como componentes da fração volumosa: T1 - 100:0; T2 -67:33; T3 - 33:67 e T4 - 0:100.

A proporção dos ingredientes nas dietas encontra-se na Tabela 1 e as composições químicas dos alimentos e das dietas, nas Tabelas 2 e 3, respectivamente.

O experimento teve duração de 78 dias - 15 para adaptação dos animais às dietas e 63 dias experimentais, divididos em três períodos de 21 dias. Após o período de adaptação, após jejum de 14 horas, procedeu-se às pesagens dos animais, repetidas em intervalos de 21 dias, de modo que as pesagens intermediárias foram realizadas sem jejum prévio.

A alimentação foi fornecida à vontade, em duas refeições diárias (7h30 e 15h), sendo ajustadas diariamente de forma a manter as sobras em 5 a $10 \%$ do total fornecido. Foram feitas anotações diárias da quantidade de ração fornecida e das sobras, para cada animal, e amostragens das silagens, do grão de soja, do concentrado e das sobras. As amostras diárias foram agrupadas em amostras semanais, que constituíram amostras compostas, para cada período de 21 dias, que foram devidamente identificadas e armazenadas em freezer para posteriores análises.

O rendimento de carcaça de cada animal foi determinado pelo cálculo do peso da pesagem das meiacarcaças esquerda e direita em relação ao peso vivo do animal em jejum.

Tabela 1 - Proporção dos ingredientes nas dietas experimentais, com base na matéria seca

Table 1 - Ingredient compositon of experimental diets on dry matter basis

\begin{tabular}{|c|c|c|c|c|}
\hline \multirow[t]{2}{*}{$\begin{array}{l}\text { Ingrediente (\%) } \\
\text { Ingredient (\%) }\end{array}$} & \multicolumn{4}{|c|}{$\begin{array}{c}\text { Nível de silagem de sorgo (\% } \\
\text { Sorghum silage level (\%) }\end{array}$} \\
\hline & 0 & 33 & 67 & 100 \\
\hline $\begin{array}{l}\text { Silagem de capim-braquiarão } \\
\text { Brachiaria brizantha silage }\end{array}$ & io 60,0 & 40,20 & 19,80 & 0,00 \\
\hline $\begin{array}{l}\text { Silagem de sorgo } \\
\text { Sorahum silaqe }\end{array}$ & 0,00 & 19,80 & 40,20 & 60,0 \\
\hline $\begin{array}{l}\text { Fubá de milho } \\
\text { Ground corn }\end{array}$ & 33,89 & 31,67 & 29,41 & 27,23 \\
\hline $\begin{array}{l}\text { Grão de soja }{ }^{1} \\
\text { Soybean grain }{ }^{1}\end{array}$ & 4,54 & 6,76 & 9,02 & 11,20 \\
\hline $\begin{array}{l}\text { Uréia } \\
\text { Urea }\end{array}$ & 1,00 & 1,00 & 1,00 & 1,00 \\
\hline $\begin{array}{l}\text { Sulfato de amônia } \\
\text { Ammonium sulfate }\end{array}$ & 0,10 & 0,10 & 0,10 & 0,10 \\
\hline $\begin{array}{l}\text { Sal } \\
\text { Salt }\end{array}$ & 0,25 & 0,25 & 0,25 & 0,25 \\
\hline $\begin{array}{l}\text { Fosfato bicálcico } \\
\text { Dicalcium phosphate }\end{array}$ & 0,20 & 0,20 & 0,20 & 0,20 \\
\hline $\begin{array}{l}\text { Premix mineral }^{2} \\
\text { Mineral mixture }^{2}\end{array}$ & 0,02 & 0,02 & 0,02 & 0,02 \\
\hline
\end{tabular}

${ }^{1}$ Adicionado na ocasião da alimentação dos animais.

${ }^{1}$ Added at the feeding time.

${ }^{2}$ Composição: sulfato de cobre $(22,5 \%)$, sulfato de cobalto $(1,4 \%)$ sulfato de zinco $(75,4 \%)$, iodato de potássio $(0,5 \%)$ selenito de sódio $(0,2 \%)$.

${ }^{2}$ Composition: copper sulfate (22.5\%); cobalt sulfate (1.4\%); zinc sulfate (75.4\%); potassium iodate (0.5\%); sodium selenite $(0.2 \%)$. 
Tabela 2 - Teores de matéria seca (MS), matéria orgânica (MO), proteína bruta (PB), nitrogênio insolúvel em detergente neutro (NIDN) e em detergente ácido (NIDA), extrato etéreo (EE), fibra em detergente neutro (FDN) e em detergente ácido (FDA), fibra em detergente neutro corrigida para cinzas e proteína (FDNcp), carboidratos nãofibrosos (CNF), carboidratos não-fibrosos corrigidos para cinzas e proteína (CNFcp), lignina e fibra indigestível em detergente ácido (FDAi) dos ingredientes e concentrados e valores de nitrogênio amoniacal $\left(\mathrm{N}-\mathrm{NH}_{3}\right)$ e $\mathrm{pH}$ das silagens

Table 2 - Contents of dry matter (DM), organic matter (OM), crude protein (CP), neutral detergent insoluble nitrogen (NDIN), acid detergent insoluble nitrogen (ADIN), ether extract (EE), neutral detergent fiber (NDF), neutral detergent fiber corrected for ash and protein (NDFap), nonfiber carbohydrates (NFC), nonfiber carbohydrates corrected (NFCap), lignin, and indigestible acid detergent fiber (iADF) of ingredients and concentrates and values of $\mathrm{N}-\mathrm{NH}_{3}$ and $\mathrm{pH}$ of silages

\begin{tabular}{|c|c|c|c|c|c|c|c|}
\hline \multirow[t]{3}{*}{ Item } & \multicolumn{3}{|c|}{$\begin{array}{l}\text { Ingrediente } \\
\text { Ingredient }\end{array}$} & \multicolumn{4}{|c|}{$\begin{array}{l}\text { Concentrado } \\
\text { Concentrate }\end{array}$} \\
\hline & \multicolumn{2}{|c|}{$\begin{array}{l}\text { Silagem } \\
\text { Silage }\end{array}$} & \multirow[t]{2}{*}{$\begin{array}{c}\text { Soja grão } \\
\text { Whole soybean }\end{array}$} & \multicolumn{4}{|c|}{$\begin{array}{l}\text { Nível de silagem de sorgo } \\
\text { Sorghum silage level }\end{array}$} \\
\hline & $\begin{array}{l}\text { Braquiarão } \\
\text { B. brizantha }\end{array}$ & $\begin{array}{l}\text { Sorgo } \\
\text { Sorghum }\end{array}$ & & 0 & 33 & 67 & 100 \\
\hline MS (\%) (DM) & 22,02 & 34,35 & 92,03 & 89,75 & 89,36 & 89,29 & 89,04 \\
\hline $\mathrm{MO}^{1}(O M)$ & 92,55 & 95,23 & 95,09 & 95,96 & 96,48 & 96,69 & 95,47 \\
\hline $\mathrm{PB}^{1}(\mathrm{CP})$ & 9,00 & 6,32 & 34,20 & 17,16 & 17,15 & 17,44 & 18,20 \\
\hline $\mathrm{NIDN}^{2}(\mathrm{NDIN})$ & 50,28 & 35,56 & 19,56 & 10,01 & 12,19 & 13,64 & 13,19 \\
\hline $\operatorname{NIDA}^{2}(A D I N)$ & 36,90 & 18,38 & 6,66 & 6,78 & 7,12 & 6,89 & 6,58 \\
\hline $\mathrm{EE}^{1}$ & 1,27 & 2,24 & 17,92 & 3,68 & 3,42 & 3,52 & 3,61 \\
\hline $\mathrm{FDN}^{1}(\mathrm{NDF})$ & 74,28 & 60,59 & 13,50 & 10,52 & 10,54 & 10,68 & 10,32 \\
\hline FDNcp $^{1}$ (NDFap) & 71,98 & 57,42 & 10,21 & 9,23 & 9,32 & 9,44 & 9,21 \\
\hline $\mathrm{CNF}^{1}(N F C)$ & 8,00 & 26,08 & 29,47 & 69,10 & 69,87 & 69,55 & 67,84 \\
\hline $\mathrm{CNFCp}^{1}$ (NFCap) & 10,30 & 29,25 & 32,76 & 70,39 & 71,09 & 70,79 & 68,95 \\
\hline $\mathrm{FDA}^{1}(A D F)$ & 50,02 & 36,97 & 9,45 & 3,97 & 3,79 & 4,07 & 4,26 \\
\hline Lignina $^{1}$ (Lignin) & 10,08 & 5,13 & 3,80 & 1,32 & 1,06 & 1,02 & 1,17 \\
\hline $\mathrm{FDAi}^{1}(i A D F)$ & 35,33 & 20,31 & 2,55 & 1,32 & 1,26 & 1,22 & 1,16 \\
\hline $\mathrm{N}-\mathrm{NH}_{3}{ }^{2}\left(\mathrm{~N}-\mathrm{NH}_{3}\right)$ & 21,18 & 6,42 & - & - & - & - & - \\
\hline $\mathrm{pH}$ & 5,02 & 4,24 & - & - & - & - & - \\
\hline
\end{tabular}

$1 \%$ na MS; $2 \%$ do $\mathrm{N}$ total.

$1 \% D M ; 2 \%$ of total $N$.

Entre o $31^{\underline{0}}$ e $35^{\underline{0}}$ dias experimentais, foram coletadas amostras de aproximadamente $300 \mathrm{~g}$ de fezes, diretamente do piso, antes da primeira alimentação dos animais, para a estimativa da produção fecal, utilizando-se a fibra em detergente ácido indigestível (FDAi) como indicador interno, conforme metodologia proposta por Cochran et al. (1986). Nesse período, também foram coletadas amostras das silagens, do grão de soja, do concentrado e das sobras, que foram congeladas para posteriores análises. Após pré-secagem em estufa de ventilação forçada, a $65^{\circ} \mathrm{C}$, durante 72 horas, as amostras de fezes, sobras e alimentos foram processadas em moinho com peneira de malha de $1 \mathrm{~mm}$, sendo que as fezes e sobras foram proporcionalmente agrupadas, constituindo-se amostras compostas por animal.

As amostras de fezes, alimentos e sobras referentes à estimativa da digestibilidade foram incubadas in situ em um novilho fistulado no rúmen, utilizando-se sacos de ankom (filter bags F57), em duplicata, por um período de 144 horas. Após a incubação, os sacos foram retirados e abundantemente lavados com água de torneira e o material remanescente foi submetido à fervura em detergente ácido, durante 1 hora, para estimativa dos teores de FDAi, utilizando-se a equação:

Coeficiente de digestibilidade do nutriente $=$ $100 *$ [100-(\% de FDAi no alimento/ \% de FDAi nas fezes)* (\% do nutriente nas fezes / \% do nutriente no alimento)].

As determinações de pH e nitrogênio amoniacal/ $\mathrm{N}$ Total foram realizadas conforme Bolsen et al. (1992). O pH foi estimado com auxílio de peagômetro em amostras de $25 \mathrm{~g}$ de silagem, acrescidas de $100 \mathrm{~mL}$ de água destilada e mantidas em repouso por 2 horas. Outra amostra de 25g, adicionada de $50 \mathrm{~mL}$ de uma solução de $\mathrm{H}_{2} \mathrm{SO}_{4}, 0,2 \mathrm{~N}$, permaneceu em repouso por 48 horas em geladeira e foi submetida, em seguida, à filtragem em papel filtro do tipo "Whatman 54”. O material filtrado permaneceu em geladeira para determinações de nitrogênio amoniacal. 
abela 3 - Teores de matéria seca (MS), matéria orgânica (MO), proteína bruta (PB), nitrogênio insolúvel em detergente neutro (NIDN) e em detergente ácido (NIDA), extrato etéreo (EE), fibra em detergente neutro (FDN) e em detergente neutro corrigida para cinzas e proteína (FDNcp), carboidratos não-fibrosos (CNF), fibra indigestível em detergente ácido (FDAi), lignina e nutrientes digestíveis totais (NDT) das dietas experimentais, com base na matéria seca

Table 3 - Contents of dry matter (DM), organic matter (OM), crude protein (CP), neutral detergent insoluble nitrogen (NDIN), acid detergent insoluble nitrogen $(A D I N)$, ether extract (EE), neutral detergent fiber (NDF), neutral detergent fiber corrected for ash and protein (NDFap), nonfiber carbohydrates, (NFC), indigestible acid detergent fiber (iADF), lignin, and total digestible nutrients (TDN) of experimental diets, in \% dry matter

\begin{tabular}{lrrrr}
\hline \multirow{2}{*}{$\begin{array}{l}\text { Ingrediente (\%) } \\
\text { Ingredient (\%) }\end{array}$} & \multicolumn{4}{c}{$\begin{array}{c}\text { Nível de silagem de sorgo (\%) } \\
\text { Sorghum silage level (\%) }\end{array}$} \\
\cline { 2 - 5 } & \multicolumn{1}{c}{0} & \multicolumn{1}{c}{33} & \multicolumn{1}{c}{67} & 100 \\
\hline MS (\%) (DM) & 49,21 & 51,58 & 54,13 & 56,56 \\
MO (OM) & 93,86 & 94,56 & 95,14 & 95,28 \\
PB (CP) & 12,89 & 12,85 & 12,79 & 12,88 \\
NIDN ${ }^{1}$ (NDIN) & 34,62 & 32,63 & 30,25 & 27,33 \\
NIDA ${ }^{1}$ (ADIN) & 24,85 & 21,29 & 17,79 & 13,67 \\
EE & 2,89 & 3,32 & 3,87 & 4,41 \\
FDN (NDF) & 48,91 & 46,27 & 43,54 & 40,90 \\
FDNcp (NDFap) & 46,93 & 44,09 & 41,18 & 38,25 \\
CNF (NFC) & 29,17 & 32,12 & 34,88 & 37,16 \\
FDAi (iADF) & 21,78 & 18,82 & 15,77 & 12,81 \\
Lignina (Lignin) & 6,69 & 5,68 & 4,72 & 3,84 \\
NDT (TDF) & 58,33 & 62,65 & 68,16 & 72,68 \\
\hline
\end{tabular}

$1 \%$ do $\mathrm{N}$ total.

$1 \%$ of total $N$.

Todas as amostras foram submetidas à pré-secagem a $65^{\circ} \mathrm{C}$ em estufa ventilada, durante 72 horas e, posteriormente, foram processadas em moinho de faca tipo "Willey", com peneira de $1 \mathrm{~mm}$. As determinações de matéria seca (MS), matéria orgânica (MO), nitrogênio total (NT), extrato etéreo (EE), lignina, nitrogênio insolúvel em detergente neutro (NIDN) e em detergente ácido (NIDA) foram realizadas conforme técnicas descritas por Silva \& Queiroz (2002). Os teores de fibra em detergente neutro (FDN) e em detergente ácido (FDA) foram determinados conforme metodologia descrita por Pell \& Schofield (1993), denominada método da autoclave.

Em razão da presença de uréia nas dietas, os CNF dos concentrados foram calculados como proposto por Hall (2000): CNF $=100-[(\% \mathrm{~PB}-\%$ PB derivada da uréia + \% de uréia) + \%FDN + \%EE + \%cinzas].

Os teores de nutrientes digestíveis totais (NDT) foram obtidos pela seguinte equação: NDT $=$ PBD +
FDND + CNFD + 2,25 x EED, em que PBD, FDND, CNFD e EED significam, respectivamente, proteína bruta digestível, fibra em detergente neutro digestível, carboidratos não-fibrosos digestíveis e extrato etéreo digestível (NRC, 2001).

Para estimativa da taxa de passagem (Kp), utilizaram-se as equações recomendadas pelo NRC (2001): $\mathrm{Kp}=3,054+0,614 \mathrm{X} 1$ e Kp = 2,904+1,375X1-0,020X2, indicadas para determinação da taxa de passagem de forrageiras úmidas e de alimentos concentrados, respectivamente, em que $\mathrm{X} 1$ equivale ao consumo de matéria seca em relação ao peso vivo e X2, à percentagem de concentrado na dieta.

Os dados obtidos foram submetidos às análises de variância e de regressão pelo programa SAEG 8.0 Sistema de Análises Estatísticas e Genéticas (Universidade Federal de Viçosa, 1998). Os modelos foram selecionados adotando-se como critério a significância dos coeficientes de regressão pelo teste “t”, o coeficiente de determinação e a variável estudada.

\section{Resultados e Discussão}

A silagem de capim-braquiarão apresentou pH em torno de 5,02 e relação nitrogênio amoniacal/ $\mathrm{N}$ total de 21,2\% (Tabela 3), além de coloração escura e forte odor de amônia. Segundo Muck \& Pitt (1993), altos valores de pH e nitrogênio amoniacal indicam fermentação clostrídica da forrageira ensilada, caracterizando uma silagem com altos níveis de ácido butírico, teores de $\mathrm{N}$ $\mathrm{NH}_{3} / \mathrm{NT}$ superiores a $10 \%, \mathrm{pH}$ acima de 5,0 e odor característico de ácido butírico ou amônia.

$\mathrm{O} \mathrm{pH}$ da silagem foi de 4,24 e o $\mathrm{N}-\mathrm{NH}_{3} / \mathrm{NT}$, de 6,42\% (Tabela 3). De acordo com McDonald et al. (1991) e Muck \& Pitt (1993), esses valores permitem classificá-la de boa qualidade.

Os consumos médios diários dos nutrientes, suas respectivas equações de regressão, seus coeficientes de variação e de determinação, ajustados em função dos níveis de silagem de sorgo, encontram-se na Tabela 4.

De modo geral, apenas o consumo de FDN, expresso em diferentes formas, não foi influenciado $(\mathrm{P}>0,05)$ pelos níveis de silagem de sorgo na fração volumosa das dietas.

O consumo de matéria seca, expresso em kg/dia e em \%PV, apresentou tendência linear crescente com o aumento dos níveis de silagem de sorgo na dieta, refletindo a qualidade superior da silagem de 
sorgo em relação à de capim. O baixo teor de MS do capim-braquiarão no momento da ensilagem, certamente contribuiu para a ocorrência de fermentações indesejáveis e o conseqüente comprometimento da palatabilidade da silagem.

Segundo Erdman (1993), a exata razão da diminuição do consumo da forragem ensilada ainda não é conhecida. Porém, os produtos finais da fermentação (ácidos lático, acético e, principalmente, butírico), presentes em altos níveis em silagens com alto teor de umidade, podem afetar negativamente o consumo. Assim, acredita-se que o incremento da silagem de sorgo na dieta melhorou sua palatabilidade, refletindo positivamente no consumo de MS. Além disso, a silagem de capim apresentou teores de FDN, FDA, FDAi e lignina maiores que a silagem de sorgo, o que propiciou menor concentração energética às dietas com maiores níveis de silagem de capim. Conforme Church (1993), o uso de alimentos ricos em fibra e pouco digestíveis geralmente reduz o consumo de MS, como conseqüência da quantidade de material indigestível que ocupa espaço dentro do rúmen, causando distensão física do epitélio ruminal. Entretanto, de acordo com Van Soest (1994), em silagens de baixa qualidade, o nível de consumo não atinge esse limite e, provavelmente, outros fatores estão envolvidos na redução do consumo.
Feijó et al. (2001) forneceram silagens de sorgo e de Panicum maximum cv. Mombaça a vacas de descarte da raça Nelore e verificaram consumos de matéria seca de 2,8 e 2,2\% PV, respectivamente, para aquelas que receberam silagens de sorgo e de capim, e atribuíram esses resultados à qualidade inferior da silagem de capim, que, ao contrário da silagem de sorgo, apresentou características de fermentações indesejáveis.

O consumo de MO também elevou-se linearmente com o acréscimo da silagem de sorgo à dieta, certamente em decorrência do aumento no consumo de matéria seca total. Comportamento semelhante foi verificado para o consumo de $\mathrm{PB}$, que aumentou 0,0033 kg/unidade de silagem de sorgo adicionada. Esse comportamento também deve-se ao aumento no consumo de MS, uma vez que as dietas eram isoprotéicas.

Os consumos de EE e CNF também apresentaram tendência linear crescente $(\mathrm{P}<0,01)$, provavelmente em razão do aumento no consumo de matéria seca total e do maior teor desses nutrientes nas dietas com maiores proporções de silagem de sorgo.

Não se observou, no entanto, efeito $(\mathrm{P}>0,05)$ dos níveis de silagem de sorgo sobre os consumos de FDN, expressos em kg/dia e em \%PV, registrando-se valores médios de 3,63 e 0,88, respectivamente, que podem ser atribuídos ao aumento no consumo de MS,

Tabela 4 - Médias, equações de regressão, coeficientes de variação (CV) e de determinação ( $\left.r^{2}\right)$, obtidos para os consumos de matéria seca (MS), matéria orgânica (MO), proteína bruta (PB), extrato etéreo (EE), fibra em detergente neutro (FDN), carboidratos não-fibrosos (CNF) e nutrientes digestíveis totais (NDT), em função dos níveis de silagem de sorgo

Table 4 - Means, regression equation (equations), coefficients of variation (CV) and determination ( $\left.r^{2}\right)$ for intakes of dry matter (DM), organic matter (OM), crude protein (CP), ether extract (EE), neutral detergent fiber (NDF), nonfiber carbohydrates (NFC), and total digestible nutrients (TDN) according to different levels of sorghum silage (SS)

\begin{tabular}{|c|c|c|c|c|c|c|c|}
\hline \multirow[t]{2}{*}{ Item } & \multicolumn{4}{|c|}{$\begin{array}{l}\text { Nível de silagem de sorgo (\%) } \\
\text { Sorghum silage level (\%) }\end{array}$} & \multirow[t]{2}{*}{$\begin{array}{l}\text { Equação } \\
\text { Equation }\end{array}$} & \multirow[t]{2}{*}{ CV (\%) } & \multirow[t]{2}{*}{$\mathrm{r}^{2}$} \\
\hline & 0 & 33 & 67 & 100 & & & \\
\hline \multicolumn{8}{|c|}{$\begin{array}{c}\text { Consumo (kg/dia) } \\
\text { Intake ( } \mathrm{kg} / \text { day) }\end{array}$} \\
\hline MS (DM) & 6,93 & 8,59 & 8,89 & 9,29 & $\hat{\mathrm{Y}}=7,3210+0,0220 * * \mathrm{SS}$ & 12,87 & 0,84 \\
\hline $\mathrm{MO}(\mathrm{OM})$ & 6,51 & 8,12 & 8,41 & 8,83 & $\hat{\mathrm{Y}}=6,8834+0,0217 * * \mathrm{SS}$ & 12,79 & 0,85 \\
\hline $\mathrm{PB}(C P)$ & 1,01 & 1,23 & 1,27 & 1,37 & $\hat{\mathrm{Y}}=1,0550+0,0033^{*} * \mathrm{SS}$ & 11,59 & 0,90 \\
\hline $\mathrm{EE}$ & 0,23 & 0,32 & 0,35 & 0,36 & $\hat{\mathrm{Y}}=0,2548+0,0011 * * \mathrm{SS}$ & 10,94 & 0,83 \\
\hline $\mathrm{FDN}(N D F)$ & 3,24 & 3,84 & 3,73 & 3,71 & $\hat{\mathrm{Y}}=3,63$ & 14,10 & \\
\hline CNF (NFC) & 2,19 & 2,92 & 3,36 & 3,43 & $\hat{\mathrm{Y}}=2,3536+0,0124 * * \mathrm{SS}$ & 13,85 & 0,89 \\
\hline $\operatorname{NDT}(T D N)$ & 4,04 & 5,36 & 6,06 & 6,74 & $\hat{\mathrm{Y}}=4,2314+0,0263 * * \mathrm{SS}$ & 13,01 & 0,97 \\
\hline \multicolumn{8}{|c|}{$\begin{array}{c}\text { Consumo }(\% \mathrm{PV}) \\
\text { Intake }(\% B W)\end{array}$} \\
\hline MS (DM) & 1,74 & 2,08 & 2,20 & 2,19 & $\hat{\mathrm{Y}}=1,8298+0,0044 * * \mathrm{SS}$ & 11,45 & 0,78 \\
\hline FDN (NDF) & 0,81 & 0,93 & 0,92 & 0,88 & $\hat{\mathrm{Y}}=0,88$ & 12,75 & \\
\hline
\end{tabular}

** Significativo a $1 \%$ de probabilidade pelo teste $\mathrm{t}$.

** Significant at $1 \%$ of probability by $t$ test. 
visto que as dietas apresentaram teores decrescentes de FDN (48,91\% para 40,9\%) com o incremento da silagem de sorgo.

O consumo de NDT também elevou linearmente com os níveis de silagem de sorgo, estimando-se acréscimos de 0,0263 kg por unidade de silagem de sorgo adicionada às dietas. Esse aumento no consumo de NDT resultou da maior ingestão de MS e da maior concentração de NDT nas dietas com níveis mais elevados de silagem de sorgo (Tabela 4). Fato semelhante foi observado por Souza et al. (2003), ao avaliarem o desempenho de bovinos mestiços Holandês x Zebu alimentados com dietas à base de silagem de sorgo e pré-secado de capim-tifton 85. Esses autores constataram aumentos no consumo de NDT à medida que elevaram a participação de silagem de sorgo nas dietas. Por sua vez, Cavalcante et al. (2002), ao avaliarem a substituição de feno de capimtifton 85 por silagem de milho, não evidenciaram diferenças entre os consumos de NDT e concluíram que as dietas foram nutricionalmente equivalentes, uma vez que, com exceção do consumo de EE, que aumentou, o consumo dos demais nutrientes e a digestibilidade não foram influenciados pelas dietas.

Os consumos de PB e NDT estimados pelo NRC (1996) para bovinos castrados, com peso vivo inicial de $400 \mathrm{~kg}$ e ganho de peso de aproximadamente $1,0 \mathrm{~kg} /$ dia, são de 0,97 e 5,8 kg/dia, respectivamente. Os valores observados para os consumos de PB (de 1,01 a 1,37 kg/dia) evidenciaram o suprimento dos requerimentos deste nutriente em todas as dietas. Entretanto, somente aquelas dietas contendo 67 e $100 \%$ de silagem de sorgo na fração volumosa supriram as exigências de NDT para ganhos de peso de 1,0 kg/dia.

Na Tabela 5 são apresentadas as médias, as equações de regressão e os coeficientes de variação e de determinação, obtidos para ganhos médios diários de peso vivo, conversão alimentar e rendimento de carcaça, em função dos níveis de silagem de sorgo na fração volumosa das dietas. Observou-se que o ganho médio diário de peso vivo dos animais aumentou linearmente $(\mathrm{P}<0,05)$ com a inclusão da silagem de sorgo na fração volumosa das dietas, em razão do aumento linear no consumo de MS com os níveis de silagem de sorgo. Segundo Mertens (1994), 60 a 90\% do desempenho animal é diretamente relacionado ao consumo de MS.

Do mesmo modo, Feijó et al. (2001), avaliando o efeito do fornecimento de silagens de sorgo e de P. maximum cv. Mombaça associadas a duas fontes energéticas (grão de milho e casca de soja a $0,8 \%$ do PV) sobre o desempenho de vacas de descarte, observaram que, independentemente da fonte energética utilizada, os animais alimentados com silagem de sorgo apresentaram ganho de peso superior (1,9 kg/dia) àqueles que receberam silagem de capim (1,05 kg/dia).

Restle et al. (2003) avaliaram o desempenho de bezerros de corte alimentados com silagens de Brachiaria plantaginea, com ou sem inoculante bacteriano e com uma mistura de silagem de milho e de sorgo na proporção 50:50, adotando relação volumoso concentrado 65:35, e também relataram maiores ganhos de peso para os animais que receberam a mistura de silagem de milho e de sorgo.

Resultados semelhantes foram obtidos por Ferreira et al. (1995), que, ao fornecerem, ad libitum, silagem de milho (SM), silagem mista de capimelefante (1/2 SCE) e (1/2) milho e a combinação das silagens de milho e de capim-elefante (1/3 SM + 2/3 SCE), com base na matéria natural, suplementadas com $1 \mathrm{~kg}$ de concentrado/novilha/dia, verificaram maior ganho de peso para as novilhas suplementadas com SM, embora os consumos de MS das silagens e total tenham sido semelhantes. Os autores atribuíram o maior ganho de peso das novilhas suplementadas com SM ao seu alto valor energético.

Entretanto, Souza et al. (2001), ao estudarem o desempenho de bovinos de corte, substituíram o présecado de capim-tifton 85 por silagem de sorgo, nas proporções de 0 32, 68 e 100\% em dietas com relação volumoso:concentrado 60:40, e observaram comportamento quadrático para o ganho de peso dos animais, estimando ganho máximo de 1,25 kg/dia para dietas contendo 60,95\% de silagem de sorgo. Contudo, ressalta-se que o teor de MS do pré-secado utilizado por esses autores foi de 53,65\% e, provavelmente não sofreu fermentações indesejáveis, o que pode ter refletido positivamente no desempenho dos animais.

A conversão alimentar não foi influenciada pela inclusão de silagem de sorgo nas dietas, registrando-se valor médio de 8,98. Entretanto, apesar de a análise de variância não ter evidenciado influência $(\mathrm{P}>0,05)$ das diferentes dietas sobre essa variável, houve tendência numérica de melhor conversão alimentar com o aumento da participação da silagem de sorgo. Entretanto, o valor observado para a conversão alimentar $(8,77)$ dos animais alimentados com a dieta com silagem de sorgo foi inferior aos 7,89 observados 
por Souza et al. (2001) quando forneceram dietas contendo $60 \%$ de silagem de sorgo e $40 \%$ de concentrado a bovinos de corte. O rendimento de carcaça também não foi influenciado $(\mathrm{P}>0,05)$ pelas dietas, registrando-se valor médio de 52,52\%, que foi semelhante à média de 52,94\% observada por Souza et al . (2001).

Na Tabela 6 são apresentadas as médias, as equações de regressão e os coeficientes de variação obtidos para os coeficientes de digestibilidade aparente total dos nutrientes, em função dos níveis de silagem de sorgo. Com exceção do EE e dos CNF, houve aumento no coeficiente de digestibilidade dos nutrientes com o acréscimo da silagem de sorgo.

$\mathrm{O}$ aumento verificado na digestibilidade aparente total da MS com o incremento da silagem de sorgo reflete a qualidade inferior da silagem de capim em relação à de sorgo. Esse resultado pode ser explicado pela diferença entre a fração fibrosa das duas silagens, uma vez que a silagem de sorgo apresentou menor teor de FDA, lignina e FDAi, sendo, portanto, mais digestível que a de capim. Dados sumarizados por Van Soest (1994), para forragens e outros alimentos, indicam que a lignina e a fibra em detergente ácido estão mais intimamente associadas à digestibilidade e a fibra em detergente neutro, ao consumo voluntário.

Como observado para o coeficiente de digestibilidade aparente total da MS, houve efeito linear crescente $(\mathrm{P}<0,01)$ do coeficiente de digestibilidade da $\mathrm{MO}$ com o incremento da silagem de sorgo. Tendência semelhante foi verificada por Souza et al. (2003), que, ao avaliarem a digestibilidade aparente em bovinos de corte recebendo dietas à base de silagem de sorgo e pré- secado de capim-tifton 85, registraram aumentos lineares nas digestibilidades aparentes de MS e MO à medida que a silagem de sorgo foi incluída na dieta. Por sua vez, Cavalcante et al. (2002), ao estudarem a substituição do feno de capim-tifton 85 pela silagem de milho para bovinos de corte, não notaram diferenças nos coeficientes de digestibilidade de MS, MO, PB e EE.

Verificou-se efeito linear $(\mathrm{P}<0,01)$ do aumento da participação da silagem de sorgo sobre a digestibilidade aparente total da $\mathrm{PB}$, estimando-se incrementos de 0,0653 unidades/unidade de silagem de sorgo adicionada, possivelmente em razão do maior teor de NIDN e NIDA da silagem de capim em relação à de sorgo (Tabela 3). Portanto, a substituição da proteína da silagem de capim pela proteína da silagem de sorgo melhorou a digestibilidade aparente da PB da dieta. Além disso, os aumentos lineares no consumo de PB com a elevação dos níveis de silagem de sorgo podem ter contribuído para uma possível redução da proporção do nitrogênio endógeno nos compostos nitrogenados fecais.

Quanto à digestibilidade aparente total da FDN, houve efeito linear crescente $(\mathrm{P}<0,01)$ com o aumento dos níveis de silagem de sorgo na dieta, provavelmente em decorrência da pior qualidade da fibra da silagem de capim, que apresentou teores de FDN, FDA, lignina e FDAi maiores que a silagem de sorgo, uma vez que os consumos médios diários de FDN não diferiram entre as dietas.

Os valores médios de taxa de passagem foram de 4,$27 ; 4,58 ; 4,70$ e $4,69 \% / h$, para dietas contendo 0,33 , 67 e $100 \%$ de silagem de sorgo na fração volumosa,

Tabela 5 - Médias, equações de regressão e coeficientes de determinação $\left(r^{2}\right)$ e de variação (CV), obtidos para os ganhos médios diários em peso vivo (GMD), conversão alimentar (CA) e rendimento de carcaça (RC), em função dos níveis de silagem de sorgo

Table 5 - Means, regression equations, coefficients of variation (CV) and determination ( $\left.r^{2}\right)$ for average daily body weight gain (ABG), feed conversion (FC) and percentage of carcass (PC) according to different levels of sorghum silage (SS)

\begin{tabular}{lccccccc}
\hline Itens & \multicolumn{3}{c}{$\begin{array}{c}\text { Nível de silagem de sorgo (\%) } \\
\text { Sorghum silage level (\%) }\end{array}$} & $\begin{array}{c}\text { Equação } \\
\text { Equation }\end{array}$ & CV (\%) & $\mathrm{r}^{2}$ \\
\cline { 2 - 5 } & 0 & 33 & 67 & 100 & & & \\
\hline $\mathrm{GMD}^{1}(A B G)$ & 0,77 & 0,96 & 1,05 & 1,09 & $\hat{\mathrm{Y}}=0,8087+0,00313 * \mathrm{SS}$ & 0,91 & 20,66 \\
$\mathrm{CA}(F C)$ & 9,24 & 9,06 & 8,84 & 8,77 & $\hat{Y}=8,98$ & 18,88 \\
$\mathrm{RC}(\%)(P C)$ & 52,08 & 52,62 & 52,79 & 52,64 & $\hat{Y}=52,53$ & 2,22 \\
\hline
\end{tabular}

* Significativo a $5 \%$ de probabilidade pelo teste $\mathrm{t}$.

* Significant at $5 \%$ of probability by $t$ test.

$1 \mathrm{~kg} /$ dia.

1 kg/day 
Tabela 6 - Médias, equações de regressão e coeficientes de variação (CV) e de determinação $\left(r^{2}\right)$, obtidos para os coeficientes de digestibilidade da matéria seca (MS), matéria orgânica (MO), proteína bruta (PB), extrato etéreo (EE), fibra em detergente neutro (FDN) e carboidratos não-fibrosos (CNF), em função dos níveis de silagem de sorgo (SS)

Table 6 - Means, regression equations, coefficients of variation (CV) and determination ( $\left.r^{2}\right)$ for apparent total digestibilities of dry matter (DM), organic matter $(O M)$, crude protein $(C P)$, ether extract $(E E)$, neutral detergent fiber (NDF), and nonfiber carbohydrates (NFC) according to different levels of sorghum silage (SS)

\begin{tabular}{|c|c|c|c|c|c|c|c|}
\hline \multirow[t]{2}{*}{ Item } & \multicolumn{4}{|c|}{$\begin{array}{l}\text { Nível de silagem de sorgo (\%) } \\
\text { Sorghum silage level (\%) }\end{array}$} & \multirow[t]{2}{*}{$\begin{array}{l}\text { Equação } \\
\text { Equation }\end{array}$} & \multirow[t]{2}{*}{ CV $(\%)$} & \multirow[t]{2}{*}{$\mathrm{r}^{2}$} \\
\hline & 0 & 33 & 67 & 100 & & & \\
\hline MS (DM) & 56,71 & 60,42 & 65,74 & 69,12 & $\hat{\mathrm{Y}}=56,6236+0,1274 * * \mathrm{SS}$ & 5,25 & 0,99 \\
\hline $\mathrm{MO}(\mathrm{OM})$ & 58,14 & 61,59 & 66,82 & 70,13 & $\hat{\mathrm{Y}}=58,0034+0,1233 * * \mathrm{SS}$ & 5,02 & 0,99 \\
\hline $\mathrm{PB}(C P)$ & 63,08 & 64,79 & 65,99 & 69,96 & $\hat{\mathrm{Y}}=62,6895+0,0653 * * \mathrm{SS}$ & 5,70 & 0,93 \\
\hline EE & 79,92 & 79,84 & 78,84 & 81,96 & $\hat{\mathrm{Y}}=80,14$ & 4,94 & \\
\hline FDN $(N D F)$ & 36,96 & 39,29 & 47,57 & 50,73 & $\hat{\mathrm{Y}}=36,2038+0,1487 * * \mathrm{SS}$ & 11,77 & 0,95 \\
\hline $\mathrm{CNF}(N F C)$ & 90,41 & 89,20 & 89,72 & 88,79 & $\hat{\mathrm{Y}}=89,53$ & 4,01 & \\
\hline
\end{tabular}

** Significativo a $1 \%$ de probabilidade pelo teste $\mathrm{t}$.

** Significant at $1 \%$ of probability, by $t$ test.

respectivamente. A relação entre a taxa de passagem (Kp\%) e os níveis de silagem de sorgo foi avaliada por meio da seguinte equação de regressão: $\mathrm{Kp}(\%)=$ $4,3541+0,0041 * *$ SS $\left(\mathrm{P}<0,01\right.$ e $\left.^{2}=0,78\right)$, em que SS corresponde ao nível de silagem de sorgo na fração volumosa das dietas. Esse aumento linear nas taxas de passagem certamente refletiu o aumento verificado no consumo de matéria seca.

\section{Conclusões}

A associação de $67 \%$ de silagem de sorgo e $33 \%$ de silagem de Brachiaria brizantha cv. Marandu apresentou-se como boa alternativa de volumoso para a alimentação de novilhos Nelore em confinamento, uma vez que promoveu consumo e ganho de peso próximos aos observados para a dieta contendo apenas silagem de sorgo. Portanto, a associação desses volumosos depende de fatores econômicos e de manejo.

A adição de níveis crescentes de silagem de sorgo (0; 33; 67 e 100\%) em substituição à silagem de Brachiaria brizantha cv. Marandu promove aumentos na digestibilidade da MS, MO, PB e FDN da dieta.

\section{Literatura Citada}

ALLEN, M.S. Physical constraints on voluntary intake of forage by ruminants. Journal of Animal Science, v.74, n.12, p.3063-3075, 1996.

ANUALPEC. Anuário da pecuária brasileira. São Paulo: FNP Consultoria \& Comércio, 2003. 400p.
BOLSEN, K.K.; LIN, C.; BRENT, B.E. et al. Effect of silage additives on the microbial succession and fermentation process of alfalfa and corn silages. Journal of Dairy Science, v.75, p.3066-3083, 1992.

CAVALCANTE, A.C.R.; PEREIRA, O.G.; GARCIA, R. et al. Consumo e digestibilidade de dietas contendo feno de capimtifton 85 e silagem de milho para bovinos. In: REUNIÃO ANUAL DA SOCIEDADE BRASILEIRA DE ZOOTECNIA, 39., 2002. Recife. Anais... Recife: Sociedade Brasileira de Zootecnia, 2002. CD-ROM. Nutrição de Ruminantes.

CHURCH, D.C. The ruminant animal - Digestive physiology and nutrition. Illinois: Waveland press, 1993. 564p.

COCHRAN, R.C.; ADAMS, D.C.; WALLACE, J.D. et al. Predicting digestibility of different diets with internal makers: Evaluation of four potential makers. Journal of Animal Science, v.63, p.1476-1483, 1986.

ERDMAN, R. Silage fermentation characteristics affecting feed intake. In: NATIONAL SILAGE PRODUCTION CONFERENCE, 1993, Syracuse. Proceedings... Syracuse: NRAES-67, 1993. p.210-219.

FEIJÓ, G.L.D.; THIAGO, L.R.L.S.; SILVA, J.M. et al. Uso de silagens e concentrados contendo milho ou casca de soja para engorda de vacas em confinamento. In: REUNIÃO ANUAL DA SOCIEDADE BRASILEIRA DE ZOOTECNIA, 38., 2001, Piracicaba. Anais... Piracicaba: Sociedade Brasileira de Zootecnia, 2001. CD-ROM.

FERREIRA, J.J.; ZUNINGA, M.C.P.; VIANA, M.C.M. et al. Silagem mista de capim-elefante e de milho no desempenho de novilhas confinadas. Revista Brasileira de Zootecnia, v.24, p.6, p.1027, 1995.

HALL, M.B. Calculation of non-structural carbohydrate content of feeds that contain non-protein nitrogen. Florida: University of Florida, 2000. p.A-25. (Bulletin 339)

MARI, L.J. Intervalo entre cortes em capim-Marandu (Brachiaria brizantha (Hochst. ex. Rich) Stapf. cv. Marandu): produção, valor nutritivo e perdas associadas à fermentação da silagem. Piracicaba: Escola Superior de Agricultura Luiz de Queiroz, 2003. 138p. Dissertação (Mestrado 
em Agronomia) - Escola Superior de Agricultura Luiz de Queiroz, 2003.

McDONALD, P.; EDWARDS, R.A.; GREENHALGH, J.F.D. et al. Animal nutrition. 5.ed. New York: Longman, 1995. 607p.

McDONALD, P.; HENDERSON, A.R.; HERON, S.J.E. The biochemistry of silage. 2.ed. Marlow: Chalcombe, 1991. 340p.

MERTENS, D.R. Regulation of forage intake. In: FAHEY JR., G.C.; COLLINS, M.; MERTENS, D.R. et al. (Eds.). Forage quality, evaluation and utilization. Madison: ASA-CSSASSSA, 1994. p.450-493.

MUCK, R.E.; PITT, R.E. Ensiling and its effect on crop quality silage. In: SILAGE PRODUCTION FROM SEED TO ANIMAl, 67., 1993, New York. Proceedings... New York: NRAES, 1993. p.57-66.

NATIONAL RESEARCH COUNCIL - NRC. Nutrient requirements of dairy cattle. 7. ed. Washinton, D.C.: 2001. 381p.

NUSSIO, L.G.; RIBEIRO, J.L.; PAZIANI, S.F. et al. Fatores que interferem no consumo de forragens conservadas. In: VOLUMOSOS NA PRODUÇÃO DE RUMINANTES, 2003, Jaboticabal. Anais... Jaboticabal: Funep, 2003. p.27-49.

PELL, A.N.; SCHOFIELD, P. Computerized monitoring of gas production to measure forage digestion in vitro. Journal of Dairy Science, v.76, p.1063-1073, 1993.

RAYMOND, W.F. The nutritive value of forage crops. Advances in Agronomy, v.21, p.1-108, 1969.

RESTLE, J.; NEUMANN, M.; BRONDANI, I.L. et al. Avaliação da silagem de capim Papuã (Brachiaria plantaginea) por meio do desempenho de bezerros de corte confinados. Ciência Rural, v.33, n.4, p.749-756, 2003.

RIBEIRO, K.G.; PEREIRA O.G.; SOUZA, P.P.S. et al. Composição bromatológica de silagens de Brachiaria decumbens, tratadas com inoculante microbiano, em diferentes idades. In: REUNIÃO ANUAL DA SOCIEDADE BRASILEIRA DE ZOOTECNIA, 39., 2002, Recife. Anais... Recife: Sociedade Brasileira de Zootecnia, 2002. (CD-ROM).
SILVA, D.J.; QUEIROZ, A.C. Análise de alimentos: métodos químicos e biológicos. 3.ed. Viçosa, MG: Universidade Federal de Viçosa, 2002. 235p.

SOUZA, V.G.; PEREIRA, O.G.; VALADARES FILHO, S. C. et al. Consumo, ganho em peso e conversão alimentar de bovinos de corte recebendo rações à base de silagem de sorgo e présecado de capim-tifton 85. In: REUNIÃO ANUAL DA SOCIEDADE BRASILEIRA DE ZOOTECNIA, 38., 2001, Piracicaba. Anais... Piracicaba: Sociedade Brasileira de Zootecnia, 2001. CD-ROM. Nutrição de ruminantes.

SOUZA, V.G.; PEREIRA, O.G.; VALADARES FILHO, S. C. et al. Consumo, digestibilidade e parâmetros ruminais de bovinos de corte recebendo dietas contendo silagem de sorgo e présecado de capim-tifton 85. In: REUNIÃO ANUAL DA SOCIEDADE BRASILEIRA DE ZOOTECNIA, 40., 2003. Santa Maria. Anais... Santa Maria: Sociedade Brasileira de Zootecnia, 2003. CD-ROM. Nutrição de ruminantes.

UNIVERSIDADE FEDERAL DE VIÇOSA - UFV. SAEG. Sistema de análises estatísticas e genéticas. Versão 8.0 . Viçosa, MG: 1998. 150p.

Van SOEST, P.J. Nutritional ecology of the ruminant. 2.ed. London: Constock Publishing Associates, 1994. 476p.

ZAGO, C.P. Híbridos de milho e sorgo para silagem: características agronômicas e nutricionais. In: SIMPÓSIO SOBRE MANEJO ESTRATÉGICO DA PASTAGEM, 1., 2002, Viçosa, MG. Anais...Viçosa, MG: Universidade Federal de Viçosa, 2002. p.351-371.

Recebido em: 03/09/04 Aceito em: 29/06/05 